\title{
A Prospective Study of Lipid Profile and BMI as Risk Factors in MI in Young [<40 Yrs] In Rural Background
}

\author{
Yadavendra C Reddy ${ }^{1}$ \\ ${ }^{1}$ Department of Medicine, Government Medical College Nalgonda, Telangana, India
}

\section{Abstract}

Background: In recent years' cardiovascular disease is the leading cause of mortality and morbidity worldwide in both male and female is accepted. The urbanisation has made its impact on the rising incidence of MI in India. One should not overlook however that MI in rural areas has doubled as well. This study is aimed at studying the Dyslipidaemia and Body mass index as risk factors in MI in young in rural background. Subjects and Methods: This prospective observational study was done in General Medicine Department at SVS hospital during July 2007 to July 2009. Out of 100 patients admitted with MI 20 selected and studied based on inclusion and exclusion criteria. Results: The study showed patients with high LDL $>100 \mathrm{mg} / \mathrm{dl}$ and low $\mathrm{HDL}<35 \mathrm{mg} / \mathrm{dl}$ were prone for MI than other individuals. Furthur it was shown that patients with BMI>30 had increased risk for MI than otherwise. It was also observed that female preponderance was more compared to males. Conclusion: The study shows that dyslipidaemia and abnormal BMI do contribute to MI in young in rural background.

Keywords: Body mass index, dyslipidaemia, high density lipoproteins, low density lipoproteins, Myocardial infarction.

Corresponding Author: Dr. Yadavendra C Reddy, Department of Medicine, Government Medical College, Nalgonda, Telangana, India.

Received: September 2019

Accepted: September 2019

\section{Introduction}

In recent years cardiovascular disease is the leading cause of mortality and morbidity in both male andfemale populations. $^{[1,2]}$ Cardiovascular disease is considered as multifactorial disease, which is affected by the environment and genetic factors. Traditional risk factors such as smoking, drinking, diabetes, dyslipidaemia can increase the risk of cardiovascular disease. ${ }^{[3]}$ Among the many cardiovascular risk factors, dyslipidaemia is considered as the most important risk factor, which is a strong predictor for cardiovascular outcomes after AMI. Lipid profile evaluation including total cholesterol, triglycerides, low density lipoproteins and high density lipoproteins allows an assessment of CVD risk. A growing evidence indicates that elevated concentration of triglycerides, total cholesterol, low density lipoproteins and decreased high density lipoproteins accelerate the development of atherosclerotic plaques. ${ }^{[4-7]}$ Approximately $90 \%$ of myocardial infarction results from an acute thrombus that obstructs an atherosclerotic coronary artery. The interaction between LDL cholesterol and HDL cholesterol indicated that risk is $\mathbf{1 1 . 6}$ fold higher for men with LDL cholesterol levels above 160mg/dl and HDL cholesterol levels below $35 \mathrm{mg} / \mathrm{dl}$ as compared to men with LDL cholesterol below 100mg/dl and HDL cholesterol above $45 \mathrm{mg} / \mathrm{dl}$. Hypertriglyceridaemia is often associated with low high density lipoprotein cholesterol that contributes to cardiovascular disease and stroke. Hypertriglyceridaemia is associated with rheological and impaired fibrinolytic mechanisms that can contribute to atherothrombosis. ${ }^{[9]}$ Overweight and obesity are well known risk factors for CVD. ${ }^{[10]}$ A large metaanalysis of cause specific mortality in the general population has shown increased mortality from ischaemic heart disease with increasing BMI. ${ }^{[11]}$ Additionally elevated BMI seems to be a strong risk factor for the development of heart failure among paients with type 1 diabetes mellitus. ${ }^{[12]}$

\section{Subjects and Methods}

This prospective observational study was done in Department of General Medicine at SVS hospital from July 2007 to July 2009. Out of 100 patients admitted 20 were selected based on inclusion and exclusion criteria.

\section{Inclusion criteria}

1. Age less than 40 years

2. ST elevation $>1 \mathrm{~mm}$ in limb leads more than $2 \mathrm{~mm}$ in chest leads which is present in two contiguous leads.

\section{Exclusion criteria}

1. Age more than 40 years

2. previous AMI

3. Incomplete data of lipid files

4. patients with chronic liver dysfunction, malignant tumors and other serious medical disorders

5. Patients who were taking medications of lipid lowering 
such as statins and fibrates.

All the patients admitted were subjected to detail history regarding their age, h/o DM, HTN and family history. All the patients were calculated BMI based on their height and weight applying the formula. Routine investigations were done after admission. An ECG was taken for every patient on arrival and every hourly intervals there after 4hrs.patient were done CK [MB] and Trop I at the time of admission. Serum lipid profiles were done in patient after the acute event.

\section{Results}

Of the 20 patients male incidence was more with 16[80] and females 4 [20] showing 4:1 preponderence.

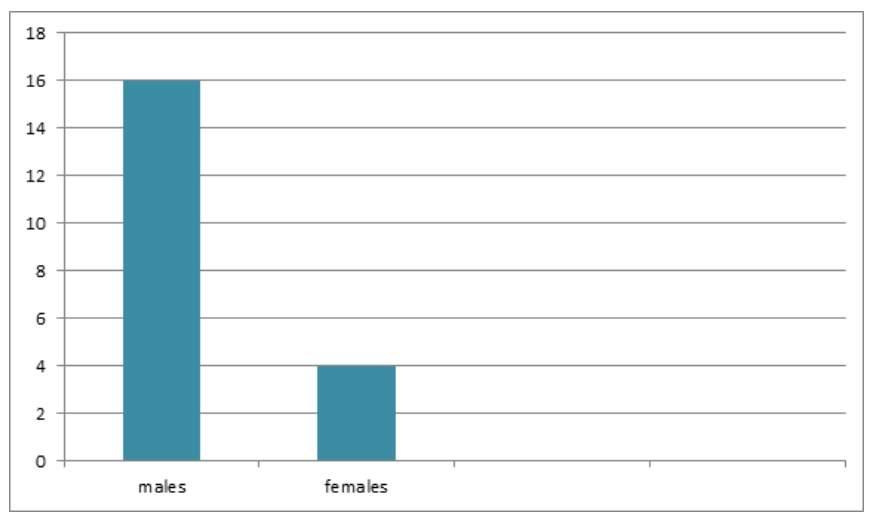

Figure 1: Gender distribution.

Of the 20 patients $75 \%$ are between $31-40$ years and with inclination for 36-40 years [55\%] and least between 21-25 [10\%]. The incidence is more between 31-40 years group.

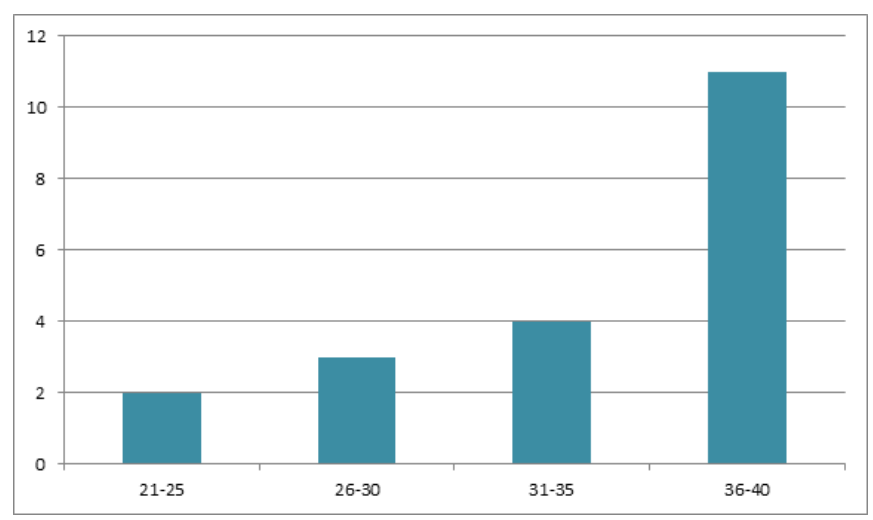

Figure 2: Age distribution.

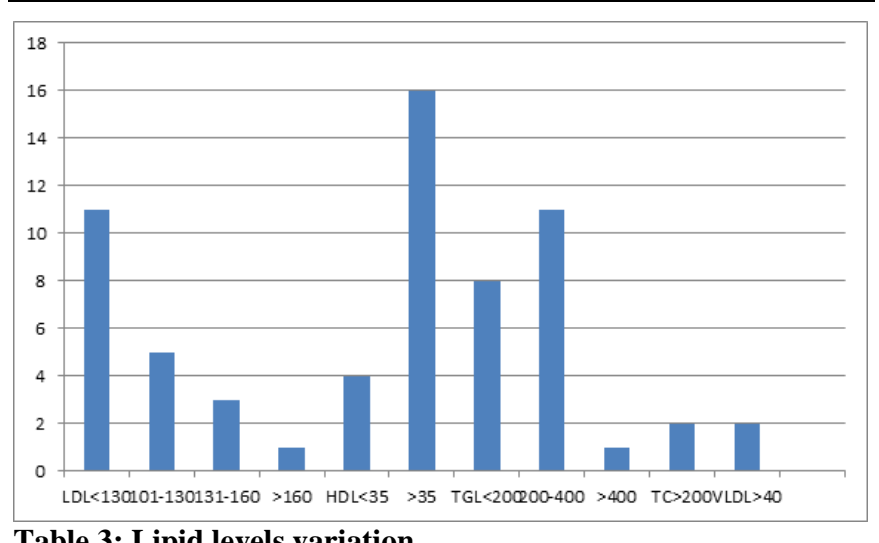

Table 3: Lipid levels variation.
Of the 20 patients with LDL cholesterol values were graded as <100mg/dl [11] 101-130 [5] 131-160mg/dl [3] and $>160 \mathrm{mg} / \mathrm{dl}$ [1] Patients with HDL cholesterol were graded as $\mathrm{HDL}<35 \mathrm{mg} / \mathrm{dl}$ [4] and HDL $>35 \mathrm{mg} / \mathrm{dl}[16]$

Patients with TGL were graded TGL<200[8], 200-400 [11] and $>400[1]$

Patients with TC>200-2; patients with VLDL>40-2

With BMI as reference range no. of patients with $\mathrm{BMI}>30-5$; BMI 23-30 are 4;BMI 19-23are 11.

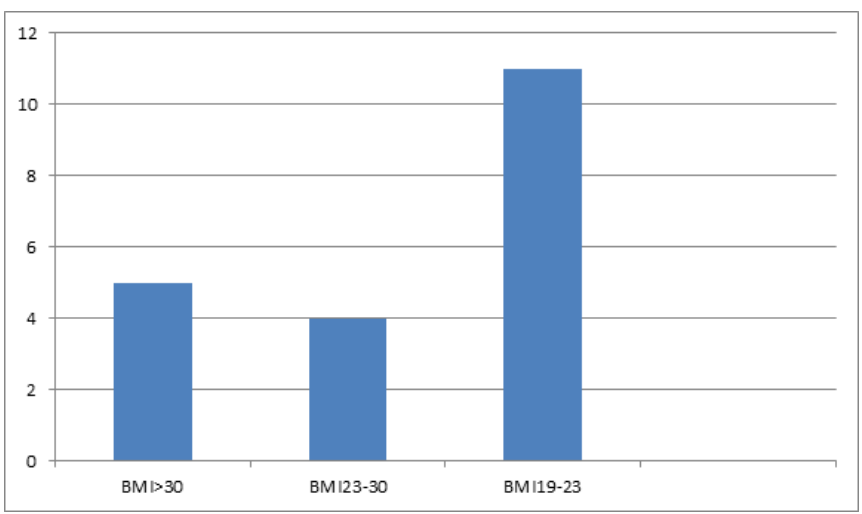

Table 4: BMI variation.

\section{Discussion}

In our study of lipid profile and BMI as risk factors in young we have taken $<40$ years as upper age limit of 100 patients 20 patients who were of age less than 40 years were enrolled in the study. The studies in relation to MI in young Jit Singh et $\mathrm{al}^{[13]}$ have taken upper age limit as 45 years. The maximum incidence in this study was between 36-40[55\%] and least between 21-25 [10\%] in coincidence to 35-40[45\%] in Jit Singh et al study ${ }^{[13]}$ The male to ale ratio was more compared to Jit Singh, ${ }^{[13]}$ study [4:1 vs 3.2:1].The cut off level for LDL cholesterol in patients with vascular event was less than $100 \mathrm{mg} / \mathrm{dl}$. In these studies we had 9[45\%] above that level which shows strong correlation of dyslipidaemia with MI in young patients in contrast to $66.7 \%$ in Remacle et al study. ${ }^{[14]}$ Similarly 4 [20\%] had HDL less than $35 \mathrm{mg} / \mathrm{dl}$ and $50 \%$ had hypertriglyceridaemia mostly females in whom it is an independent risk factor. Total cholesterol was greater than $200 \mathrm{mg} / \mathrm{dl}$ in 2 [10\%] of patients. In our study we had BMI>30 for 5 patients; 23-30 there were 4 patients; BMI 1923 were 11 patients indicating that $45 \%$ of patients had BMI as risk factor contributing to $\mathrm{MI}$ in young. In our study we had 4 patients with abnormal BMI having MI approximately $20 \%$ compared to $15 \%$ in Vestberg et al study. ${ }^{[15]}$

\section{Conclusion}

This study reveals that dyslipidaemia and BMI along with other risk factors do contribute to morbidity and mortality in MI. Therefore having a healthy lifestyle may prevent this cardiac hazard.

\section{References}

1. Mathers CD, Lancar D. Projections of global maturity and burden of disease from 2002 to 2030.plus Med 2006;3:e442

2. Zhang CV,Ji F,Yu X,Wang X.Factors associated with unattained LDL 
cholesterol goals in Chinese patients with acute coronary syndrome one year after PCI.Medicine 2017;96:e5469

3. Lennep JERV.Risk factors for coronary heart disease:implications of gender.cardiovacular research 2002 Feb 15;53[3]538-49.

4. Yong W,Qi B,Xu J,Chen S,Age and sex related differences in lipid profiles of patients hospitalised with AMI in East China.J. CLINICAL Lipidology2014;8:562-567

5. Perk J,Backer GD,Gokhle H,Developed with special contribution of the European Association for cardiovascular prevention and rehabilitation[EAPCR].European guidelines on cardiovascular disease prevention in clinical practise[version $20 \mathrm{~F}$ ].Int Journal of Behaviour Medicine 2012;19:403-88

6. Yusuf S,Hawken,onupu s,effect potentially modifiable risk factors associated with MI in 52 countries[the INTERHEART study]case control study on hetil 2006;147-675.

7. Schekein HA,loos BG.Inflammatory mechanisms linking periodontal disease to cv disease.J clinical Periodontal 2013;40:557

8. Goswami k and bandyopadhyay[2003];lipid profile in middle class Bengali population of Kolkata .Indian J of clinical biochem 2003 july;18[2]:127-130.
9. Tanne D,koren morag N,graff e2001:blood lipids and first ever stroke/tia the bezafibrate infarction prevention registry:high triglycerides constitute an independent risk factor,Circulation 2001 dec11;104[24]:2892-2897.

10. Go As,Mozaffarian D,Roser VL,et al.Heart Disease and stroke statistics-2013-update-a report from the American heart association Circulation 2013;127; e6-e245

11. Whitlock G,Lewington S,Sherliken P, et al.BMI and cause specific mortality in 900000 adults.collaborative analyses of 57 prospective studies Lancet 2009;373:1083-96

12. Westberg d,Rosenfen a,Olsson $\mathrm{m}$,et al relationship between overweight and obesity with hospitalisation for heart failure in 20,985 patients with type 1 DM-A population based study for Swedish national diabetes registry.Diabetes care 2013;36:2857-61.

13. Journal of Association of Physicians JAPI2001;49:32

14. Joussen Remacle-Risk Factors in a young population with Acute MIone year prospective study-service de cardiologie France-Am Cardiol Anjeiol[paris]2006 Aug;55[4]:204-9.

15. Daniel Vestberg,Anila Rosengen-Relationship between overweight,obesity and MI-Diabetes Care2013Sep;36[9]:2857-2861

Copyright: () the author(s), 2019. It is an open-access article distributed under the terms of the Creative Commons Attribution License (CC BY 4.0), which permits authors to retain ownership of the copyright for their content, and allow anyone to download, reuse, reprint, modify, distribute and/or copy the content as long as the original authors and source are cited.

How to cite this article: Reddy YC. A Prospective Study of Lipid Profile and BMI as Risk Factors in MI in Young [<40 Yrs] In Rural Background. Acad. J Med.2019;2(2):51-53.

DOI: dx.doi.org/10.21276/ajm.2019.2.2.14

Source of Support: Nil, Conflict of Interest: None declared. 